\title{
Grupo de Estudos e Pesquisa em Informática aplicada à Educação (GEPIE)
}

\section{Soraia Silva Prietch, Tatiana Annoni Pazeto, Gilleanes Thorwald Araujo Guedes, Renato Moraes Silva}

Curso de Sistemas de Informação - Universidade Federal de Mato Grosso (UFMT)

Rodovia Rondonópolis-Guiratinga, KM 06 (MT 270) Bairro Sagrada Família

\author{
78.735-901 - Rondonópolis - MT - Brazil \\ soraia@ufmt.br, \{tpazeto, gtaguedes\}@gmail.com, \\ flarenatms @yahoo.com.br
}

O GEPIE (Grupo de Estudos e Pesquisa em Informática aplicada à Educação), foi criado em 2006 possuindo como área de concentração predominante a Ciência da Computação, envolvendo as linhas de pesquisa Experiências em cursos de Licenciatura em Computação, Ferramentas de Software Educacional, Informática na Educação Especial, Informática na Escola e Tecnologia da Informação.

O objetivo geral do grupo é articular o ensino, pesquisa, e extensão, incentivando a formação continuada dos cidadãos, visando à melhoria na educação do ensino básico e de computação.

Como objetivos específicos do GEPIE têm-se os seguintes:

- Envolver os estudantes de Licenciatura em projetos de pesquisa, para proporcionar uma formação mais ampla e sólida, ciente de que o foco do curso visa sua futura atuação em Instituições de Ensino;

- Consolidar parcerias com as escolas de ensino básico (fundamental e médio), a fim de oportunizar a integração entre pesquisa, ensino e extensão;

- Agregar gradualmente os estudantes de Sistemas de Informação ao grupo, com a finalidade de buscar parcerias de empresas locais e de fomentar contribuições na área técnica.

Os três membros docentes integrantes do GEPIE são: Dr. Gilleanes Thorwald Araujo Guedes, Doutoranda Soraia Silva Prietch e Dra. Tatiana Annoni Pazeto, todos professores da UFMT. Atualmente, o grupo conta com 07 estudantes desenvolvendo seus trabalhos de conclusão de curso. Os três professores mencionados são orientadores dessas monografias, em três linhas diferentes.

Almejando dar continuidade aos trabalhos desenvolvidos pelo grupo, pretende-se a médio prazo: elaborar e propor Programas de Pós-Graduação stricto-sensu na área de Computação no Estado de Mato Grosso, tendo como uma das linhas de interesse a Informática na Educação, incentivando a pesquisa dos alunos nessa área; consolidar e fortalecer o envolvimento dos estudantes de Graduação em projetos de pesquisa aplicados a referida área; e, iniciar e fortalecer parcerias externas à Instituição. 